\title{
Response to comment by Smith on the 2021 EUGOGO guidelines
}

\author{
George J Kahaly' and Luigi Bartalena ${ }^{2}$
}

${ }^{1}$ Department of Medicine I, Johannes Gutenberg-University (JGU) Medical Center, Mainz, Germany and ${ }^{2}$ Department of Medicine and Surgery, University of Insubria, Varese, Italy

\section{Dear Editor,}

Thank you for giving us the opportunity to respond to the comment of Dr Smith (1) on 'The 2021 EUGOGO guidelines for the medical management of Graves" orbitopathy (GO)' (2).

These guidelines, officially endorsed by the European Society of Endocrinology and unanimously supported by the international consortium 'European Group on Graves' orbitopathy, EUGOGO' encompassing 25 expert centers on GO, aimed to mirror the current evidencebased management of this complex disease (2). Although far from optimal, both i.v. glucocorticoids and oral mycophenolate, either alone or in combination, have been shown to be effective and well-tolerated with a beneficial efficacy/safety ratio $(3,4)$. Both treatments are available worldwide, are affordable to patients and physicians, and have been administered for years, if not decades. Both have been shown to positively impact the quality of life (5), overall ophthalmic symptoms and signs $(5,6)$, eye muscle motility, and, to a lesser extent, exophthalmos (6). Although the primary endpoint was not achieved at week 12 in the EUGOGO trial, post-hoc analysis did demonstrate significant improvement at week 24 (after completion of mycophenolate treatment), as well as sustained significant amelioration at week 36 (5). In the Chinese trial of mycophenolate monotherapy (6), exophtahlmos, diplopia, and eye muscle motility markedly improved at weeks 12 and 24. Finally, 'real-world' efficacy and safety of mycophenolate (with dual antiproliferative mechanism on T and B cells, as well as on target fibroblasts) in patients with active, moderately severe-to-sight-threatening GO was demonstrated over a 4-year observation period (7).
The authors of this response are in line with Dr Smith that the antiinsulin-like growth factor 1 receptor inhibiting monoclonal antibody, teprotumumab is a very promising drug for the management of active and moderate-tosevere GO (8), and this is repeatedly and clearly stated in the text part, the table of recommendations, and in the legend of box three (2). However, guidelines are 'made for everybody', offering evidence-based recommendations, which should be possible to apply and follow worldwide. As this FDA-cleared drug is currently available and eventually affordable in the US only, for the writing task force and for the 48 expert contributors to these guidelines on GO, currently teprotumumab cannot be regarded as the first line treatment of this complex clinical condition. Furthermore, long-term efficacy in general and safety data in particular (i.e. reported hearing loss, cognitive decline, and amyloid encephalopathy, etc.) $(8,9)$ are pending and warranted.

\section{Declaration of interest}

The authors have no conflicts of interest in addition to those declared in the original guideline manuscript.

\section{Funding}

This Letter to the Editor did not receive any specific grant from any funding agency in the public, commercial or not-for-profit sector.

\section{References}

1 Smith TJ. Comment on the 2021 EUGOGO clinical practice guidelines for the medical management of Graves' orbitopathy. European Journal (c) 2021 European Society of Endocrinology Printed in Great Britain
Published by Bioscientifica Ltd. 
of Endocrinology 2021185 L13-L14. (https://doi.org/10.1530/EJE-210861)

2 Bartalena L, Kahaly GJ, Baldeschi L, Dayan CM, Eckstein A, Marcocci C, Marino M, Vaidya B, Wiersinga WM \& EUGOGO. The 2021 European group on Graves' orbitopathy (eugogo) clinical practice guidelines for the medical management of Graves' orbitopathy. European Journal of Endocrinology 2021185 G43-G67. (https://doi. org/10.1530/EJE-21-0479)

3 Lee ACH, Riedl M, Frommer L, Diana T \& Kahaly GJ. Systemic safety analysis of mycophenolate in Graves' orbitopathy. Journal of Endocrinological Investigation 202043 767-777. (https://doi. org/10.1007/s40618-019-01161-z)

4 Riedl M, Kolbe E, Kampmann E, Kramer I \& Kahaly GJ. Prospectively recorded and MedDRA-coded safety data of intravenous methylprednisolone therapy in Graves' orbitopathy. Journal of Endocrinological Investigation 201538 177-182. (https://doi. org/10.1007/s40618-014-0227-x)

5 Kahaly GJ, Riedl M, Konig J, Pitz S, Ponto K, Diana T, Kampmann E, Kolbe E, Eckstein A, Moeller LC et al. Mycophenolate plus methylprednisolone versus methylprednisolone alone in active, moderate-to-severe Graves' orbitopathy (MINGO): a randomised, observer-masked, multicentre trial. Lancet: Diabetes and Endocrinology 20186 287-298. (https://doi.org/10.1016/S22138587(18)30020-2)

6 Ye X, Bo X, Hu X, Cui H, Lu B, Shao J \& Wang J. Efficacy and safety of mycophenolate mofetil in patients with active moderate-to-severe Graves' orbitopathy. Clinical Endocrinology 201786 247-255. (https:// doi.org/10.1111/cen.13170)

7 Xian NQQ, Alnahrawy A, Akshikar R \& Lee V. Real-world efficacy and safety of mycophenolate mofetil in active moderate-to-sightthreatening thyroid eye disease. Clinical Ophthalmology 202115 1921-1932. (https://doi.org/10.2147/OPTH.S305717)

8 Kahaly GJ, Douglas RS, Holt RJ, Sile S \& Smith TJ. Teprotumumab for patients with active thyroid eye disease: a pooled data analysis, subgroup analyses, and off-treatment follow-up results from two randomised, double-masked, placebo-controlled, multicentre trials. Lancet: Diabetes and Endocrinology 20219 360-372. (https://doi. org/10.1016/S2213-8587(21)00056-5)

9 Hoang TD, Nguyen NT, Chou E \& Shakir MK. Rapidly progressive cognitive decline associated with teprotumumab in thyroid eye disease. BMJ Case Reports 202114 e242153. (https://doi.org/10.1136/ bcr-2021-242153)

Received 17 September 2021

Accepted 1 October 2021 